\title{
Parents' Attitudes towards the Implementation of Arabic as an Additional Language in Dubai: An Exploratory Case Study
}

\author{
Reem J. Razem \\ The British University in Dubai (BUiD), Dubai, UAE
}

\begin{abstract}
As part of the Ministry of Education (MoE) language policies, the UAE government made Arabic language a compulsory subject for non-speakers in all private schools. The UAE government stipulates that private schools must offer a core programme in Arabic as a second language. Thus, non-Arab expatriates are required to study Arabic as an Additional Language (AAL) from Grade 1 to Grade 9. This qualitative case study aims to explore the attitudes of parents towards the implementation of Arabic as an Additional Language (AAL) in one of the private British schools in Dubai, wherein AAL has been rated 'Acceptable'. This exploration is a snapshot of attitudes held by parents as key stakeholders in the triad of school, teachers, and parents' partnership towards the learning and teaching of AAL- whether approving or disapproving of it. It will illuminate some of the arising issues related to potential gaps between the implementation of AAL (practice) and the MoE framework (Theory). Ultimately, this paper aims to uncover challenges and proffer recommendations. To enhance the implementation of $\mathrm{AAL}$ in schools, this paper will propose potential parental engagement initiatives that can yield valuable policy decisions.
\end{abstract}

Index Terms - Arabic language, second language learning, parental attitudes, parental engagement, case study, discourse analysis, educational policy

\section{INTRODUCTION}

In the UAE, the official language is Arabic, yet the percentage of expatriates who live in Dubai is 91.3\% (Dubai Statistics Center, 2016). This demographic imbalance resulted in English language dominance as the Lingua Franca (Randall \& Samimi, 2010). This created a deep concern towards Emirati cultural identity especially the loss of mother tongue, Arabic Language (AL). However, the UAE reflects its commitment to preserving and empowering AL to enable it to regain its status. The UAE National Agenda 2021 underlines that "Arabic will re-emerge as a dynamic and vibrant language, expressed everywhere in speech and writing as a living symbol of the nation's progressive Arab-Islamic values" (UAE Vision 2021, 2019).

At the national level, several initiatives were proclaimed to enhance the learning of AL such as the establishment of a dedicated educational facility at Zayed University to promote the teaching and learning of Arabic for non-Arabic speakers (Sambidge, 2012). As part of the Ministry of Education (MoE) language policies, the government made AL a compulsory subject for non-speakers in all private schools (Randall \& Samimi, 2010). The UAE government stipulates that private schools must offer a core programme in Arabic as a second language (UAE Government, 2018). Thus, nonArab expatriates are required to study Arabic as an Additional Language (AAL) from Grade 1 to Grade 9, and schools should provide lessons four times a week (KHDA, 2019) (see Appendix A). The aim of AAL is to enhance "their (expatriates') understanding of the local culture and give them significant opportunities and advantages in later life" (KHDA, 2016). Hence, the learning of AAL can be conducive of cross-cultural understanding and appreciation of the local values, as it could offer better career prospects. Though AAL is not explicitly and officially mentioned as a 'Policy', schools that do not provide it are fined as it is considered a violation under the Executive Council Resolution No. (2) of 2017 (KHDA, 2017). According to Souza and Del Olmo (2019), language policy is what the government does officially through legislation and judicial decisions to determine how languages are used to meet national priorities, hence AAL fits this definition. Thus, this paper will discuss AAL as it pertains to language-related educational policies in the UAE.

Since AAL 'policy' has been imposed in a top-down approach, leading to a sense of disenfranchisement amongst numerous stakeholders, significant challenges arose (Heck, 2009), for example, the need for revamping the Arabic curriculum, providing teacher training opportunities in AAL, motivating students to learn it (Bell, 2016), and the challenge for the majority of expat parents (who do not know any Arabic) was helping their children in learning AAL ("Arabic in Foreign Private Schools" na). Moreover, parents voiced their concerns in the media over their children's lack of proficiency after years of learning Arabic in Dubai schools (Clarke, 2016; Ahmed, 2012). This coincided with the KHDA's school inspection reports which revealed that the majority of Dubai schools have reached an 'Acceptable' evaluation in teaching AAL (Knowledge Group, 2016). This highlights a need to explore the reasons behind the shortcomings of implementing AAL in schools. 
As the MoE is constantly honing its educational policies to ensure that the programs developed in its schools comply with international standards, MoE has lately devised 'The 2017 framework for teaching and learning AAL' (See Appendix B) in private schools and determined three key parameters that reflect language proficiency: functions, context and content, and type and level of text (MoE, 2017). One empirical indicator that MoE has added as a national goal, which measures the progress in Arabic toward the 2021 National Agenda, is to ensure that 90 percent of students in the ninth grade have a proficiency in Arabic (MoE, 2017). Yet, this seems to target Emirati students only and indicate a significant policy gap as there is no specific government targets for the expatriate students.

Although schools, teachers and students are affected by language policies that are implemented, parents are considered the guardians of students, end-users and key stakeholders, and have certain academic expectations for their children. From the review of related literature, it is obvious that the vantage point of parents is rarely studied. In addition, "a bottom-up approach to education reform fosters sustainable and 'deep' educational change that is driven by a common social vision among key stakeholders" (Warner \& Burton, 2017). According to Fowler (2013) "although students are the direct clients of most policies in education, ...their parents are the indirect, behind-the scenes clients. The parents become players in the evaluation arena much more frequently than their children do" (p. 255). Therefore, this study will explore the attitudes of parents towards the implementation of AAL.

The main purpose of this qualitative study is to explore the attitudes of parents towards the implementation of AAL (that received a rating of 'Acceptable') in one of the private British schools in Dubai. This exploration is a snapshot of attitudes held by parents as key stakeholders in the triad of school, teachers, and parents' partnership (Sanders \& Epstein, 2005) towards the learning and teaching of AAL- whether approving or disapproving of it. It will illuminate some of the arising issues related to potential gaps between the implementation of AAL (practice) and the MoE framework (goals). Ultimately, this paper aims to uncover challenges and formulate recommendations, which are elicited from parents. To enhance the implementation of AAL in schools, this paper will propose potential parental engagement initiatives that can yield valuable policy decisions.

Parents as end-users and key stakeholders are affected by the outcomes of implementing AAL in schools. Hence, the key research question is:

- What are the parents' attitudes towards the implementation of AAL in a Dubai private school?

The sub-questions that will assist in unpacking and answering the key research question include:

- Do parents' support the AAL requirement or not and why?

- What roles are parents playing -if any- in supporting the teaching and learning of AAL?

The data collection instrument used in the qualitative study is in depth semi-structured interviews. To answer the research questions and achieve their objectives, this paper will analyse and interpret collected data, discuss and report findings and their implications, and finally conclude with recommendations elicited from parents' views.

Given the recent announcement of His Highness Sheikh Mohammed Bin Rashid Al Maktoum: "We have a national agenda for Arabic language, and we have issued directives to work further through studies and initiatives to cement the Arabic language as a language of life" ("Emirates 24/7," 2018), this paper is considered timely. In addition, this research will explore a perspective that is under researched, given the dearth of scholarly research on expatriate parents' attitudes of AL learning matters in the UAE and the Arab world. Furthermore, AAL implementation faces many challenges and the KHDA inspection reports allude to the need to enhance the teaching and learning of AAL in schools since students are not attaining expected proficiency levels according to the MoE framework. Therefore, exploring parents' attitudes will bring insight into what they think works and what is needed for AAL to work. This will contribute to the existing literature and provide original insights from a different vantage point. While this study is contextualised within the context of Dubai school system, it could have resonance for many expatriates living in the UAE and GCC.

For the purpose of better exploring parental attitudes, an overview of three related conceptual frameworks is presented. These include: parental engagement and second language learning motivation, heritage and non-heritage learners, and language attitudes.

\section{A. Parental Engagement and Second Language Learning Motivation}

The notion of parental engagement, involvement or encouragement is perceived as multifaceted and multidimensional in nature. This aligns with Fan and Chen's (2001) definition of 'parental involvement' which comprises five dimensions: educational expectation/aspiration for children, communication with children about schoolrelated matters, parental supervision, parental participation in school activities, and general parent involvement. From their meta-analysis study that scanned the literature on parental involvement and academic achievement, the scholars concluded that a positive influence of parental involvement impacts students' academic achievement and parental expectation/aspiration for their children's education achievement as it also shows the strongest relationship with students' academic achievement. Likewise, Gardner (2010) posits in his Motivation battery, the 'Parental Attitude Model', in which parents play a crucial role whether actively or passively in influencing their children's motivation to learn a Second Language (L2), either encourage or discourage. Similarly, Dornyei (2005) conceptualized the L2 Motivational Self-System and included 'Parents' Influence' as a factor that impacts learners' motivation to learn languages. The seminal research of the aforementioned scholars resonates strongly with the purpose of this study and 
the need to illuminate parental involvement as a factor that impacts students' language learning motivation and achievement in AAL within the context of Dubai.

\section{B. Heritage and Non-heritage Learners}

Scholars in the field of AAL have acknowledged a crucial nominal definition as they classified students according to their background into three separate groups: "learners of Arab descent, non-Arab Muslim learners, and learners of different ethnic and cultural backgrounds other than the first two groups" (Husseinali, 2006, p. 103). Hence, the first two are commonly called Heritage Learners (HLs) versus Non-Heritage Learners (NHLs) (Husseinali, 2006). While HLs can affiliate themselves to AL through family, religion, or identity, NHLs assume no cultural or personal affiliations to AL. This is also linked to parental roles and encouragement to learn AAL. Parents who affiliate themselves to an Arab or Muslim background are generally more encouraging, involved and proactive in their children's learning of AL (Martin, 2009; Zabarah, 2015). Since their attitudes towards Arabic culture, Arab people and Arabic language are mostly favourable, their children are being held accountable for their progress and the parental expectation is high in matter of AL academic achievement.

\section{Language Attitudes}

Several Second Language Acquisition (SLA) studies have correlated attitudes with motivations to learn a Target Language (TL). Smith (1971) defines attitude as a relatively enduring organization of beliefs around an object or a situation, predisposing one to respond in some preferential manner. An attitude is relatively enduring because it is learned. Oskamp and Schultz (2005) explicate, “A child's attitudes are largely shaped by its own experiences with the world, but this is usually accomplished by explicit teaching and implicit modelling of parental attitudes" (p.126). In the 'Parental Attitude Model', Gardner and Lambert (1972) postulate four main attitude dimensions, which include attitudes towards: learning languages in general, the TL culture, learning the TL in specific, and the speakers of TL. When students enter the class with favourable attitudes about the target language, people and culture, they are more likely be open to perceive, respond, and learn the TL. Therefore, favourable parental attitudes and feelings towards learning AAL are needed to increase the motivation of the students in language learning classes. For the purposes of this paper and as means to capture the construct of parental attitudes, these dimensions will be adopted in framing the interview questions and guiding the data analysis.

To capture the attitudes of parents towards AAL, there are two theoretical lenses that underpin the study at hand. The first emerges from the seminal work of Gardner and Lambert (1972) which culminated in the 'Parental Attitudes Model' and interlinked parents' attitudinal constructs with children's language learning motivation and achievement. Some of the many ways parent exert attitudinal influence are "through discussion, by encouraging participation in foreign language exchange programmes and excursions, helping the child with homework, encouraging the child to read material written in the foreign language and by making the target language country the destination for a family holiday" (Young, 1994, p. 85).

The second lens is related to the attitude towards the TL, which links to the French sociologist Pierre Bourdieu's (1991) theory of language status and prestige and the notion of Linguistic Capital. Individual attitudes toward foreign languages are strongly influenced by the special status of a language and its perceived significance and prestige of economic, social and cultural capital. Within the context of Dubai and due to the demographic reality, AL status has been in the decline. Therefore, this study adopts Gardner and Lambert's (1972) 'Parental Attitudes Model' and Bourdieu's (1991) Linguistic Capital, as they all guide the study instrument, analysis and discussion.

\section{REVIEW OF LITERATURE}

This review is composed of selected comparable, parallel and local empirical studies that include two or more of the following keywords: Arabic language, second/foreign language acquisition/learning, parent, influence, engagement, attitude. The studies were analysed and synthesized by applying Machi and McEvoy's (2012) 'The Six Steps of the Literature Review' model. The relevant and current comparable studies that investigated parents' attitudes towards learning a foreign language were conducted in Slovenia (Lesnik, Bremen, \& Greek, 2013) and Catalonia (Wilson, 2012) On the other hand, parallel studies investigated parents' attitudes and learning Arabic as a second/foreign/additional language in the USA (Husseinali, 2006; Zabarah, 2015; Sehlaoui \& Mousa, 2016; Al-Alili \& Hassan, 2017). However, local studies from the UAE context that partially discussed parents' attitudes, include: Hamidaddin (2008), TahaThomure (2008), Al-Hilali (2014), Baker \& Hourani (2014), the Knowledge Group qualitative report (2016).

The initial critical review of research revealed that most studies used quantitative methods and questionnaires as data collection instrument. Therefore, qualitative methods were rarely used. Moreover, three major variables emerged when approaching parents' attitudes and second/foreign language learning: parents' background, parents' perception of language status and significance, and parents' perceptions of their own roles in their children's language learning.

\section{A. Parents' Background: Heritage versus Non-heritage}

One of the parallel studies conducted in four states in the USA, concluded that parents' heritage/ethnic background impacts their attitudes toward language learning which in turn impacts children's learning of TL (Al-Alili \& Hassan, 2017). The scholars noted a discrepancy between the attitudes and expectations of Arabic heritage versus non-Arabic 
speaking parents regarding learning AL. "Arabic-speaking parents were significantly more involved than the nonArabic-speaking parents" (Al-Alili \& Hassan, 2017, p. 14). This confirms Husseinali's (2006) results that parental attitudes toward AL learning play a crucial role as it highlights heritage and non-heritage learners' differing interests. Alili and Hassan (2017) also concluded that while Muslim non-Arab parents wanted their children to learn Arabic so they would be able to read and understand the Qur'an, Arab parents wanted their children to maintain their Arabic identity and culture, and NH parents encouraged their children to learn Arabic for instrumental reasons, to access job opportunities both in the USA and Middle East. Hence, parents' background can steer them towards encouraging or discouraging their children's learning of AAL.

\section{B. Parents' Perception of Language Status}

According to Wilson (2012), Catalan was considered unimportant compared to English, which is regarded as a dominant language with a very high status. The perception of the significance and utility of the language plays an important role in parental encouragement to learn that language (Lesnik, Bremen, \& Greek, 2013). Similarly, Arabic is on demand as it is considered 'a critically needed language' in the USA and this is reflected by parents' encouraging their children to learn it (Husseinali, 2006; Zabarah, 2015; Sehlaoui \& Mousa, 2016; Al-Alili \& Hassan, 2017). In the UAE, the majority of parents had a favourable attitude towards learning AAL as they perceived it to be an essential language to learn while living in the UAE (The Knowledge Group, 2016). While heritage parents' rationale for learning Arabic is the fact that it is the language of the Qur'an and the heritage language (Hamidaddin, 2008), NH parents stressed that the utility of the language is of most importance (Sehlaoui \& Mousa, 2016). However, according to AlHilali (2014) and Taha-Thomure (2008), parents believed that Arabic in Dubai is not used outside the classroom and that it has a lower status compared to English.

\section{Parents' Perceptions of Their Own Roles}

Wilson posits that "for decades now, researchers have been aware of the influence that parental encouragement, or lack thereof, can have on individual's motivation to learn L2" (2012, p. 44). In her study, Wilson emphasizes the lack of studies that investigate the parents' attitudes and their influence on their children. Likewise, Baker and Hourani (2014) explored the nature of parental involvement in Abu Dhabi schools and their findings highlighted the importance and value of parental involvement in enhancing the learning experiences of children. Yet, parents perceived their roles as recipients of information on the curriculum, pedagogy changes and their children's progress. Henceforth, knowledgesharing and curriculum updates from the school were needed, especially since parents voiced several gaps in knowledge and communication. Baker and Hourani's (2014) findings pointed to parents being disenfranchised and recommended a need to bridge the gap by conducting workshops on parent roles and responsibilities -as interventions- and opening channels of communication to express concerns raised by parents. This concurs with Hamidaddin's (2008) findings that all parents agreed that they show interest in their children's learning, yet they believe that children's learning is the responsibility of the teachers.

\section{Situating the Current Study}

From this review, a gap in the literature emerges from the lack of studies that undertake the angle of parents within a qualitative methodology and their impact on students' motivation to learn AAL in Dubai context. An investigation of the attitudes of parents of heritage and non-heritage AL learners is therefore considered required. Accordingly, it is of great importance to explore parents' attitudes toward the implementation of AAL as they have a direct impact on students' language learning development and achievement, consequently it can either hinder or encourage the success of AAL.

\section{Methodology}

Since this study will consider the parents' emotions, beliefs and attitudes and explore socially constructed meanings as parents' interpretations of the world, the interpretivist paradigm emerges as the one that provides insights into and meets the requirements of the key RQ (Walter, 2013). Mertens (1998) emphasizes that the interpretivist paradigm aims to understand society by understanding the socially constructed realities. This resonates with the main purpose of the key RQ which is: to explore parents' attitudes towards the implementation of AAL as it provides insight into their subjective perception towards the importance of $\mathrm{AL}$ and their own perceptions of their role in supporting this requirement. Therefore, because of its micro-level emphasis that aligns with the purposes of meaning making and deals with qualitative data collection methods and analysis, the interpretivist paradigm suits this study (Creswell, 2003).

\section{A. Data Collection}

Context and site: This qualitative single case study collected data from parents at a private British primary school in Dubai, in which AAL was given an 'Acceptable' evaluation by the KHDA inspection report (2017-2018) and the sample is considered convenience sampling.

Instrument: Because of time limitations, the instrument used was face-to-face 30 minute-interview, whereby semistructured questions were developed and conducted by the researcher as a result of adaptations from Gardner and Lambert's 'Parental Attitude Model' (1972) and Fan and Chen's Construct (2001). The interview questions were 
piloted on two volunteers and modified accordingly. Then the participants filled a short demographic survey (Kvale, 2007). The in-depth interview was guided by a set of relevant themes based on the theoretical framework (see Appendix C). Every interview was audio-taped and transcribed verbatim (See Appendix E). The transcripts were then sent to the interviewees for their verification and feedback.

Sample: This study used a convenience sample method of snowball sampling technique, wherein existing participants referred other parents among their acquaintances until data saturation point was reached (Naderifar, Goli, \& Ghaljaie, 2017). The inclusion criteria encompassed parents who have children attending this school and learning AAL, of Heritage (of Arab or Islamic background) and Non-Heritage (Non-Arab or Islamic background) background. Thus, six parents volunteered to participate in the interviews.

\section{B. Data Analysis}

This study implemented discourse analysis as a strategy to ensure a high-quality analysis (Kohlbacher, 2006). Discourse analysis assumes that reality is socially constructed, and meaning is fluid, which aligns with the interpretivist paradigm. While the interviews were ongoing, the researcher wrote notes which complemented the analysis of the data (Creswell, 2012). The conducted discourse analysis applied Creswell's method as "following steps from the specific to the general and as involving multiple levels of analysis" (2014, p. 196). During the analysis, a number of recurring themes were organized into tentative categories and assigned a list of codes. The codes were later categorized under the list of key themes. Initial themes that did not offer related information to the key themes were eliminated. The final write-up is highly descriptive in nature (Glesne, 2011).

\section{Limitations and Ethical Considerations}

The scope of the current study is limited to one site only, a private school in Dubai, and a small sample size of volunteer parents. Therefore, generalization is not expected. Also, this study represents a partial and limited insight into the issue at hand, since conducting a full-fledged research will entail a holistic approach that takes into consideration the school leaders', teachers, and students vantage points. It is argued that a triangulation of theoretical frameworks, vantage points, and data sources, will yield better and richer findings.

Also, investigating multiple cases with larger number of participants could reveal a wider range of attitudes. However, this will need more time, finances and resources to be fully conducted. Moreover, the fact that the sample consisted of mothers only, since fathers' participation in the study was not possible (they were unavailable or did not volunteer), this unavoidable bias and imbalance in parents' voice is thus acknowledged as a limitation. Finally, though the interviews as data collection method afford valuable data, the views and presence of the researcher might have caused bias. Additionally, not all people are efficient communicators who can be articulate in their expressions. Despite these limitations, the findings of this study will provide rich in-depth understanding and will reveal meaningful insights as primary nucleus for future studies in the field of SLA, AL, parental attitudes/involvement, and for Dubai and/or the UAE context in particular.

As for ethical considerations, this study included informed consent forms for the volunteering participants to sign (see appendix C) (Habibis, 2013). Moreover, the researcher practiced bracketing preconceived notions and biases, by using mindfulness, reflective and reflexive techniques.

\section{Trustworthiness of the Data, Site, and Sample}

This study applied Guba and Lincoln's (1994) techniques to confirm the 'trustworthiness' of the study, which include: credibility, transferability, dependability, and confirmability.

- Confirmability is assured by keeping an accurate and careful record of contacts, interviews, notes, and provide 'a chain of evidence' (Yin cited in Mertens, 1998).

- Dependability is confirmed by purposive sampling and the protection of informants' confidentiality.

- To ensure the credibility of this study, triangulation of the theoretical frameworks was applied, and the tentative interpretations of data were communicated to the participants, thus refined depending on their feedback (Silverman, 2013).

- Transferability of research is guaranteed by providing a thick description of concepts -revealed from the data.

\section{FINDINGS AND DISCUSSION}

The interviews with the parents revealed some converging and diverging attitudes towards the implementation of AAL 'Policy', some of these attitudes aligned with the literature as it will be shown in this section. In addition, the demographic table of parents' profile is presented in Appendix D. The findings of this research are bifurcated into two key themes as they relate to the theoretical underpinnings and the literature review: 'Parental Attitudes' and 'Challenges'.

While all parents concurred on the importance of AAL and approved of its implementation with no contestation, they confirmed that they never knew of the $2017 \mathrm{MoE}$ Framework and it was never communicated to them. However, all of them were content with the progress level of their children learning AL in school, which contradicts the local literature, media articles, and KHDA inspection report of 'Acceptable'. In fact, some parents who learnt Arabic conveyed that 
their children exceeded them in their knowledge of the language. Parent 1 confessed that her kids superseded her in their knowledge of AL. Yet, given that AAL was ranked 'Acceptable' and having content parents, could imply that the lack of having a reference point (AAL framework) to benchmark the progress of students' learning, keeps parents pleased with whatever attainment is achieved by their children. As a result, there is a need to investigate if the school is following the framework or not, and a need to address the gap in communication between the school and the parents while taking into consideration the criticality of setting up specific goals or targets for expat students learning AAL. Future research investigating this angle would unravel more insights.

\section{Parental Attitudes}

Attitudes towards learning languages in general: all parents were either bilingual or plurilingual and reflected a positive position towards learning languages, which supports previous research. The rationale was accorded by Parents $1,2,4,6$ as to better understand and respect other cultures and broaden one's thinking from an early age. On the other hand, Parent 3 mentioned 'social life and interactions' and Parent 5 stated 'travel' as reasons to learn AAL. Consequently, attitudes towards learning AL in Dubai were highly favourable, and the reasons provided were cultural understanding, religious motivations, and career opportunities. Parent 1 highlighted: "I think it's important to speak the language of the land we live in. Out of respect for the country and the people. It breaks down barriers and warms people of different cultures to the Arab world." While Parent 3 mentioned better prospects in career opportunities, Parent 2 stated 'understanding the Qur'an' as a crucial motivator for her and her daughters to learn AL. Accordingly, these motivations mirror the ones provided by parents in the parallel and local studies.

Attitudes towards Arabic culture: parents perceived Arabic culture to be hospitable, welcoming, embracing, and tolerant. They expressed that they love the food, songs, and the way Arabs dress. This reflects a very limited understanding of culture versus a deeper understanding of Arab traditions, heritage and values. Despite this positive general perception, they all agreed that Dubai does not fully reflect Arabic culture. "It feels like you are living in Europe", Parent 4 -who is of Lebanese origin- articulated. "It's a home away from home", Parent 1 -who is a British national- expressed. Parent 5 agreed that every expat lives in a bubble of their own culture and described Dubai residents as a 'honeycomb', "we are one, but still separated" as if every expat is living in their own 'cell'. This could reflect a lack of interculturality, and some disinterest in learning about the local culture, history, people, and possibly the local language. This implies that AAL needs to encompass engaging parents with their children in deep culture learning to meet the UAE National Agenda Vision and AAL aims.

Attitudes towards Arab people: some parents revealed that they made friends with Arabs and locals. They described Arab people as kind, helpful, hospitable, ambitious, and emotional. Parent 5 confessed that she has very limited interaction with locals, yet she feels that her son's generation is learning more about local culture than hers and mentioned the example of 'Hag-Al Laila' celebration. It can, therefore, be suggested that AAL is successfully presenting some cultural elements to expat children, and providing culture learning opportunities, which in turn meets the aim of this language 'policy'.

Attitudes towards Arabic language: most parents disagreed with the perception of Arabic being a difficult language to learn. Parent 4 compared Arabic to Mandarin: "how come people can start learning Mandarin and not Arabic! If the will is there, you can learn anything." Yet, Parent 2 explained that "because we are of Pakistani background, and we know Urdu, I believe this does help us in learning Arabic easily. A better advantage. So, for a nonMuslim it might be harder. So, I can understand why some would perceive it that way." In contrast, Parent 6 found it very difficult to learn as she explains, "I think it's very difficult, in writing, joining the letters and script right to left, even pronunciation. It is very different to Russian."

In addition, parents' perceptions of language status showed a consensus; they all regarded English as the language of prestige and utility. Parent 1 expressed her frustration for not being able to practice her Arabic and pinpointed that "the Arabic language day was a new thing for me. School should know and mark the occasion and celebrate it to embrace Arabic language, but nothing." Parent 2 elaborated "I don't feel there is a necessity to learn it". Also, Parent 5 mentioned "even when you read the recruitment pages in Dubai, you see that Arabic is preferred but English is mandatory." There are similarities between these perceptions of Arabic being in a lower status -relative to English within the context of Dubai- and those described by Taha-Thomure (2008). A possible explanation for this might not only be the lack of serious governmental action plans that can raise and revive AL but also the bottom-up action. Parent 5 denoted "learning a language is not the MoE, KHDA, schools' responsibility, it is the nation's responsibility.... You have to start from grassroots level, you can't start from tree tops. It won't really work!'”. This links to Bourdieu's Linguistic Capital notion and language status, as Arabs are resorting to learn and speak English for prestige. This highlights a need for a possible future study that solely examines the status of Arabic in Dubai context by applying Bourdieu's theory.

Parents' Background 'Heritage and Non-Heritage': contrary to the existing literature, parents' background showed very little noteworthy effect on their attitudes towards AL, people and culture (See Appendix D). Whether HL or NHL parents, they all reflected a positive view and employed their available resources (effort, time and money) to better engage their children in their AAL learning journeys. For instance, Parent 1, who belongs to a Pakistani Muslim heritage, and Parent 6 who is Russian NH, both started learning Arabic to help their children in their learning. In the same vein, Parent 2 -who is a Canadian of Pakistani Muslim origin- described living in Dubai as a motivator to learn 
Arabic, which is the same reason mentioned by Parent 5, who is a non-Muslim Canadian. Further detailed research is needed to examine the factor of parents' background on their attitudes towards learning Arabic in Dubai as it also links to Bourdieu's linguistic capital theory.

Parents' role in supporting AAL: parents perceive their role as encouraging their kids to learn by helping them do their homework, reading with them when/if they can, communicating with teachers, and giving their feedback. This finding is in agreement with the definition of active parental influence and supports previous studies.

\section{Challenges}

This discourse analysis identified some challenges to achieve the aim of AAL 'policy' as elicited from parents' perspectives in Dubai context (a bottom-up approach). These challenges relate to contextual and subjective factors. The contextual factors include:

- the lack of conducive environment to practice Arabic,

- lack of interaction with locals,

- Arabic speaking friends' preference to speak in English,

- lack of pragmatic need in the workforce.

On the other hand, the subjective factors comprise: the value given to learning and speaking Arabic and how it is being perceived. Further research, which takes these variables into account, will need to be undertaken.

\section{CONCLUSION AND RECOMMENDATIONS}

This study has shown that all parents expressed an overall positive attitude towards the AAL implementation in this school and reflected their support for an initiative to offer Arabic classes to expat parents so they would be able to support their children in learning the language while in school and enhance their cultural understanding of the place they reside and work in. However, all parents were unaware of the AAL Framework and some were surprised of the non-existence of an AAL policy. There was also a consensus amongst them on the need to engage expat parents and students in Arabic immersion experiences with the local culture. Therefore, addressing the gap in language policies related to AAL will require a comprehensive action plan and crucial policy decisions. Hence, an explicit language policy that recognizes the benefits of encouraging the learning of AL among expats "would likely complement government strategies to protect and promote Arabic since it would create a far greater number of competent Arabic language speakers" (Calafato \& Tang, 2019, p. 28). The implications of this study and its findings are presented as recommendations':

A need for an AAL policy: Devise an explicit policy for AAL, with clear goals and tools to enhance its implementation as it reflects the significance of AL and commitment of the government. This policy should be positioned within the overarching UAE National Agenda 2021 and is envisioned to include the following components:

- Communication: Schools to follow the MoE Framework and communicate it to parents.

- Culture and language: Curriculum developers to fine-tune AAL curriculum for expatriate students and embed deep local culture learning experiences to make it authentic.

- Parents engagement: Create parent education programs that explain the value of Arabic or and demonstrate ways to help children learn AAL and succeed in school. Engage Arab and local parents in assisting expat parents to learn more about the culture and AL by devising interactive cultural programs based on volunteerism or community service program. Offer immersion experiences and interactions with local culture as it should also be part of the curriculum.

- Arabic Language National Initiative: Government to offer free beginner Arabic classes to all expat parents at school premises. Schools should be awarded for doing so and parents' achievements should be highlighted and celebrated in the local media. 
ApPendix A. KHDA Curriculum Requirements For PRivate Schools in Dubai for the ACADEMic YeAR 2018/2019: ARABIC AS AN ADDITIONAL LANGUAGE

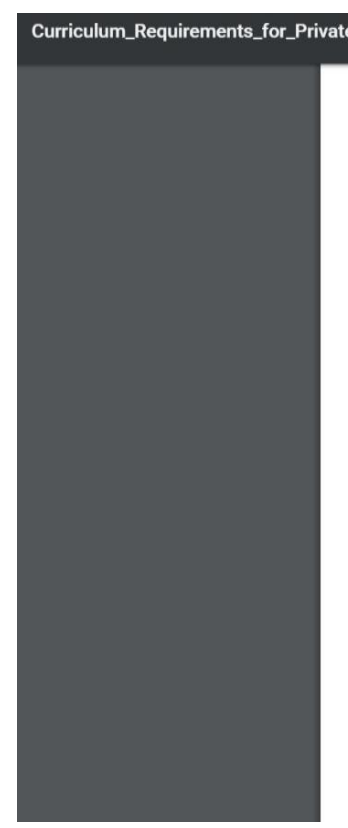

$2 / 3$

Guidelines on Arabic subject:

\begin{tabular}{|c|c|c|c|c|c|c|c|c|c|c|c|c|}
\hline \multicolumn{13}{|c|}{ ARABIC } \\
\hline Grade & 1 & 2 & 3 & 4 & 5 & 6 & 7 & 8 & 9 & 10 & 11 & 12 \\
\hline Year & 1 & 2 & 3 & 4 & 5 & 6 & 7 & 8 & 9 & 10 & 11 & 12 \\
\hline $\begin{array}{c}\text { Arabic as a first language } \\
\text { (For those who are registered in the school/KHDA } \\
\text { under an Arab passport) }\end{array}$ & \multicolumn{3}{|c|}{$\begin{array}{l}6 \text { lessons } \\
\text { per week }\end{array}$} & \multicolumn{3}{|c|}{$\begin{array}{l}5 \text { lessons } \\
\text { per week }\end{array}$} & \multicolumn{6}{|c|}{$\begin{array}{l}4 \text { lessons } \\
\text { per week }\end{array}$} \\
\hline $\begin{array}{c}\text { Arabic as an Additional Language } \\
\text { (For those who are registered in the school/KHDA } \\
\text { under any other nationality) }\end{array}$ & \multicolumn{9}{|c|}{$\begin{array}{l}4 \text { lessons } \\
\text { per week }\end{array}$} & \multicolumn{3}{|c|}{ Optional } \\
\hline
\end{tabular}

- Arab students are expected to follow the standards set in the National Curriculum Document for Arabic first language and use the MoE prescribed textbooks as the main resource in their curriculum.

- Non-Arab students are expected to follow the curriculum standards and expectations set in the 2017/2018 MoE framework for Arabic as an additional language.

- The offering of Arabic in the Early Years is not mandatory but encouraged. It is expected that schools that choose to do so will follow the standards and expectations of the MoE for Arabic in this phase of the school. 


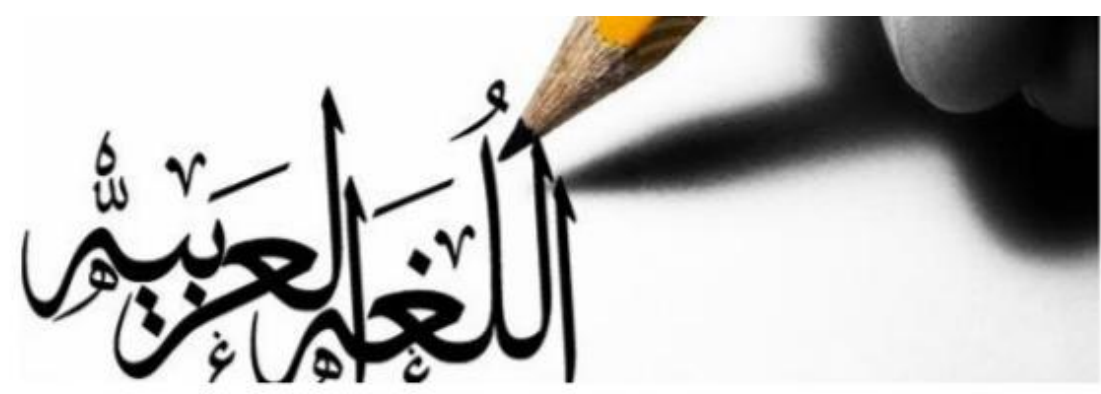

\section{Framework for Learning Arabic as an Additional Language}

\section{Introduction}

Over the years, the United Arab Emirates has accorded much attention to Arabic language. The UAE leaders have promoted the learning and using of Arabic language as they consider it a fundamental pillar of the Emirates national identity, its people's history and its deep-rooted traditions.

This framework represents an important step toward fulfiling the needs of learners of Arabic as an additional language. it is also consistent with UAE's National Agenda for 2021 with regards to the priority of improving the learning of Arabic language.

This framework focuses on enabling non-Arabic speakers who are learning Arabic to communicate in real life situations inside and outside school. This framework is based on the standards set by the American Council on the Teaching of foreign Languages (ACIF), and based on international principles and expectations applied in the teaching of foreign languages to non-native speakers. The framework is also adapted to meet the UAF's aspirations in the teaching and learning of Arabic in a manner that

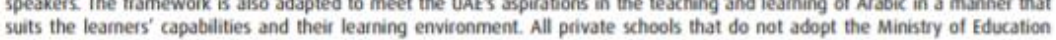
suits the learners' capabilities and their learning
curiculum are expected to apply this framework.

This framework illustrates the levels expected to be achieved by the learner in each of the four language skills (listening, speaking. reading and writing). It links the achievement of these levels to the number of years spent in studying Arabic, regardless of the learner's current grade.

This framework identifies three main fields for each level: general outcomes, language proficiency levels and performance indicators in each of the four language skills during the nine years of studying Arabic as an additional language.

The most distinguishing element of this framework is that it details the progress in language proficiency according to three key parameters: functions (to ask, inquire, narrate or describe), context and content (personal, social or general issues), and type and level of text (word, phrase, sentence or paragraph).

Accordingly, this framework constitutes an umbrella for learning Arabic as an additional language in private schools in the UAE and it is in line with the Ministry of Education requirements.

We hope this framework will contribute to encouraging schook and teachers to prepare and execute advanced study plans which include clear and practical tasks and activities, inside and outside the dassioom, in line with the expectations of this framework.

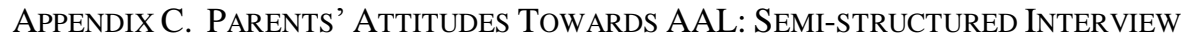

Dear Parent,

\section{About the Study \\ Consent Form}

I am conducting a research related to the implementation of Arabic as an additional language in schools.

You are invited to participate in a short interview that tries to explore parents' perspective. Your participation in this study is voluntary; however, it is very important for us to learn your opinions.

Your responses will be strictly confidential, and anonymity is safeguarded. The data from this research will be coded and reported only as a whole. Pseudo names will be used and your privacy will be of paramount importance. If you have questions at any time about the procedures, you may contact me at xxxxxx or by email at xyz@hjkl

Finally, I thank you very much for taking the time and effort to participate in this interview.

Signature:

In-depth semi-structured case study interview questions

1- Preliminary questions: The Parent Profile

$>\quad$ Sex: M/F

$>\quad$ What is your nationality?

$\quad$ What is your mother tongue?

$>\quad$ What is your ethnic or heritage background (Arab/Muslim)? your parents? 


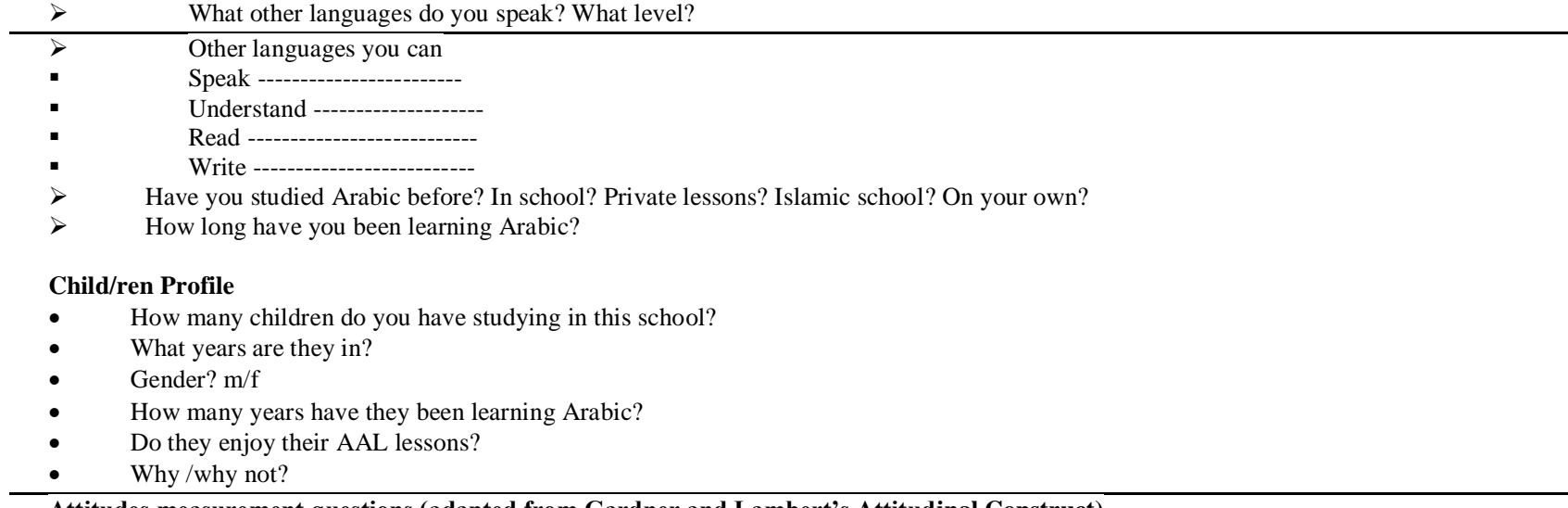

What other languages do you speak? What level?

Attitudes measurement questions (adapted from Gardner and Lambert's Attitudinal Construct)

Parents' Awareness of MoE Framework for AAL

$>\quad$ Are you aware of the $2017 \mathrm{MoE}$ framework for AAL in schools?

Parent's Attitudes towards learning languages in general

$>\quad$ What do you think of learning languages other than English? (Value second language learning)

Parents' Attitudes towards the TL culture

What do you think of Arabic culture?

Parents' Attitudes towards the speakers of TL

$>\quad$ What do you think of Arab people/speakers?

Parents' Attitudes towards the TL itself

Living in Dubai, do you think learning Arabic is an asset? For you or your child? And why?

$>\quad$ In your opinion, in what ways learning Arabic language will assist you in intercultural communication/understanding of this region 'GCC' 'Arab World' 'Muslim World'/self-actualization/achievement ..

Parents' Perceived Difficulty of Arabic Language

Some people perceive Arabic as a difficult/complex language to learn? What do you think? How to overcome this difficulty?

Parents' Perceived Roles and Involvement in AAL

$>\quad$ Are you learning Arabic with your child?

Are you helping your child in learning the language/ reading/ in doing their homework?

$>\quad$ Is your child getting help (out of school tutoring) to learn Arabic? (it reflects how much they are investing in it/interested).

$>\quad$ Have you thought/considered learning Arabic/joining Arabic courses?

$>\quad$ Where, when, how. how have your attitudes changed (if they did) after learning some Arabic?

Parents Perspectives on Suggested Policy Recommendations

$>\quad$ What do you think about this statement: "There should be a governmental initiative to offer Arabic language courses to expatriate parents for free or at a nominal cost?"

$>\quad$ Would you encourage your family, friends, others to learn Arabic in Dubai? Why?

$>\quad$ What do you suggest to improve the implementation of AAL in schools?

\section{APPENDIX D. PARENTS' Profile: DEMOGRAPHIC INFORMATION}

\begin{tabular}{|c|c|c|c|c|c|c|c|c|}
\hline $\begin{array}{l}\text { Parent } \\
\text { no }\end{array}$ & Gender & Nationality & $\begin{array}{l}\text { Heritage } \\
\text { Background }\end{array}$ & $\begin{array}{l}\text { Parent } 1^{\text {st }} \\
\text { Language }\end{array}$ & $\begin{array}{l}\text { Kids in } \\
\text { school }\end{array}$ & $\begin{array}{l}\text { Other } \\
\text { languages }\end{array}$ & $\begin{array}{l}\text { Learnt } \\
\text { Arabic }\end{array}$ & $\begin{array}{l}\text { Kids } \\
\text { like/dislike } \\
\text { Arabic } \\
\text { because... }\end{array}$ \\
\hline $\mathbf{1}$ & $\mathrm{F}$ & British & $\begin{array}{l}\text { Pakistani- } \\
\text { Muslim }\end{array}$ & English & 4 & Urdu & For a year & $\begin{array}{l}\text { Like the teacher } \\
-\quad \text { enjoys } \\
\text { languages }\end{array}$ \\
\hline 2 & $\mathrm{~F}$ & Canadian & $\begin{array}{l}\text { Pakistani- } \\
\text { Muslim }\end{array}$ & English & 2 & Urdu & No & $\begin{array}{l}\text { One daughter } \\
\text { likes the } \\
\text { teacher, the } \\
\text { other doesn't }\end{array}$ \\
\hline 3 & $\mathrm{~F}$ & American & $\begin{array}{l}\text { Indian- } \\
\text { Muslim }\end{array}$ & Hindi & 1 & English & $\begin{array}{l}\text { For three } \\
\text { months }\end{array}$ & $\begin{array}{l}\text { Loves the } \\
\text { teacher }\end{array}$ \\
\hline 4 & $\mathrm{~F}$ & American & $\begin{array}{l}\text { Lebanese-Arab- } \\
\text { Non-Muslim }\end{array}$ & Arabic & 3 & $\begin{array}{l}\text { English, } \\
\text { French }\end{array}$ & $\begin{array}{l}\text { In } \\
\text { school=13 } \\
\text { years }\end{array}$ & $\begin{array}{l}\text { Son likes the } \\
\text { teacher, } \\
\text { Daughter } \\
\text { doesn't }\end{array}$ \\
\hline 5 & $\mathrm{~F}$ & Canadian & Indian & Kutchi & 1 & $\begin{array}{l}\text { English, } \\
\text { Hindi, } \\
\text { Gujarati, } \\
\text { Marthi }\end{array}$ & $\begin{array}{l}\text { Studied } \\
\text { Arabic in } \\
\text { the UAE } \\
\text { from grade } \\
1-8\end{array}$ & $\begin{array}{l}\text { Lessons are } \\
\text { engaging and } \\
\text { relevant to } \\
\text { son's interests }\end{array}$ \\
\hline 6 & $\mathrm{~F}$ & Russian & $\begin{array}{l}\text { Non-Arab Non- } \\
\text { Muslim }\end{array}$ & Russian & 2 & English & $\begin{array}{l}\text { Is learning } \\
\text { Arabic now }\end{array}$ & Teacher is good \\
\hline
\end{tabular}


APPENDIX E. TRANSCRIBED INTERVIEWS

\begin{tabular}{|c|}
\hline Transcribed Interviews \\
\hline Parent 1 Profile \\
\hline - British mother of three \\
\hline - First language is English \\
\hline - Pakistani Muslim heritage \\
\hline - Speaks Urdu (moderately fluent and stronger in spoken language) \\
\hline - Have learnt Arabic in Dubai for a year as private lessons paid by her ( 1 hour per week) \\
\hline $\begin{array}{l}-\quad \text { Year } 2=\text { daughter, Year } 4 \text { and } 5=\text { two sons } \\
\text { Daughters spent } 1.5 \text { years learning Arbbic }\end{array}$ \\
\hline $\begin{array}{l}\text { Daughter= spent } 1.5 \text { years learning Arabic } \\
\text { Boys }=\text { spent } 2.5 \text { years learning Arabic }\end{array}$ \\
\hline $\begin{array}{l}\text { - Kids enjoy learning AAL at school = beccuse they like their teacher/ My daughter enjoys languages. } \\
>\text { Framework for learning AAL was not communicated but school sent turriculum guidel lines and } \\
\text { objectives } \\
>\text { No tutor }\end{array}$ \\
\hline$>$ No newsletters on AAL or communicated progression in Arabic \\
\hline 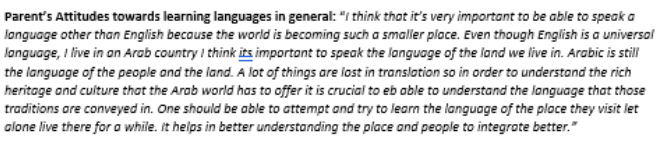 \\
\hline 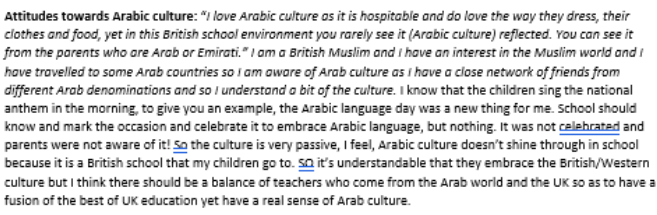 \\
\hline 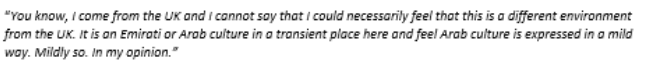 \\
\hline $\begin{array}{l}\text { Attitudes towards Arabic speakers: "Arab people ore very nice. We've never hod a problem in the UAE. Arob } \\
\text { people ore very welcoming and kind and helipful. We heve Arrobic specking friends from all over the glahe " }\end{array}$ \\
\hline 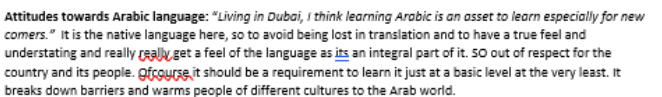 \\
\hline
\end{tabular}

Parent 2 Profile

- Canadian mother of two

- First language is Englis

Pakistani Muslim heritage

Mother tongue is Urd

Have not studied Arabic

Year $2=$ daughter, Year $3=$ daughter

Younger one really enjoys learning AAL at school = because she likes the teacher/ OIder one is a

bit behind because she didn't like last year's teacher

7 Framework for learning Aat was not communicated

Parent's Attitudes towards learning languages in general: "it is very important. We're globally connected. It's important for the kids these to speak another language to connect with other people. It's an inest re the culture ol ot ti peop

It helps with creativity and broadens your perspective and connect to other people. Instead of being in a bubble. Even for me, you know, moving to this country, it has opened my mind that a lot of people speak Arabic s

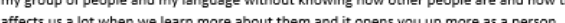

Attitudes towards Arabic culture: I was brought up abroad and here, it is very different over he and loving. You feel safer here. Being brought up in Canada and wear the Hijab, you meet people who are radst. Here, feel comfortable wearing my scart and my long shith People don't look at you in a weird way. Being in a Muslim country, and as a Muslim myself, you feel like

Attitudes towards Arabic speakers: I feel they are quite strong and bold. I've been raised in Canada and people there are very soft spoken with their hellos, please and thank yous. I feel that when Arabs are talking to each other, it seems like theyre shouting or fighting. So for me, getting used to that was a bit like, I actually realized that it is their style of talking

Attitudes towards Arabic language: As a Muslim, I can read the Qura'an but I do not understand it. So we grew up listening to it in the background of our house. It's a beautiful language and since we moved here it was very important to me that my children do learn it. I haven't learnt it myself, but I would love to learn it. Finding the right time. $\underline{\underline{s}}$ whatever my kids are learning I try to ask them and pick up the words like the fruits and vegetables and stuff.

Significance of AL: I think living anywhere in the Middle East requires people to learn Arabic. It is very important and it will help people understand the region. It is especially needed for our kinds as to have a solid grounding in the language.

As for me, since I came here I found that not only English is used a lot in communication but Urdu and Hindi as well. I thought I could learn Arabic from my interactions with people here but no I didn't learn it why I do not feel it is a necessity to learn it. Especially that I am now a homemaker. If I wanted to go
Significance of AL: "Oubvi has a good mix of Arab ond moder cultures, it is a home awoyfrom home, itrvery sofe ond very welcoming, evenththing you need you will find here, it's a very, dynomic

Perceived difficulty of the language: $x_{i}$ don't think thot Arobic is very difficult or complex language. As a person Who comes from a bockground where my mother tongue is English you con toke any longuage like chinese or
Arrobic where you hovent't seen the letters before, seing the word written in Arobic form con be very yery doun But hoving studied Arabic for a yer, and you know, I am not someone who is very strong in languages I don't think it is as difficult as people would have you believe,

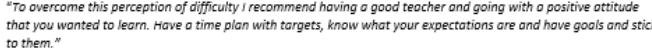
Perceived Parents' Roles: "al learnt Arabic from my children and with them in a very limited sense, so I do know how important it is for porents to be involved in their leorning ony longuage. In Arabic B, I feeli it is very repetitive in hey ore able to do, if it is o recoll tosk, yes, I can helo."

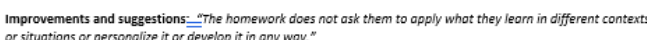

"We try and read together, so they read out loud, I think my children, bassoolveh, hove superseded me in their understanding of the longuage and I think they know the meaning of many words, which is nice to

"My kids hove no Arabic tutor because of time constroints ond financial constraints" "Truth to be told, that would be something nice."

"I think that is an amazing idea" "I would have endorsed something like thot if it had been avoiloble. It is surprising that it hasn't been offered. It is brilliont. I hope they would endorse something like that." "I do think there is a policy gap here. When people come to the UK for residency, it is now made compulsory to have a grass of English language. It is important to know the language to try and fit into the society you
live in And on the same level, when people come here (Dubail there should be an expectrotion that live in. And on the same level, when people come here (Dubai) there should be an expectrotion that
expats have some sort of a desire to learn the languge and there should be help or encourogement for expats have some sort of a desire to leant
people who do. It should be a policy."

"I think there should be more of an active engagement from the school with the porents. There should be reading programs put in ploce. Just like in English, their books ore levelled and you con trace how they're progressing. Porents can reod with their child. So there should be on Arobic reoding program. In Arobic $B$, there should be more assemblies, plays, recitols that demonstrote the children's longuage learning in different scenarios ond contexts. It would be crucial to make their learning vivid and memorable and fu

think that home work should be not so repetitive, it should be an opportunity for the child to develop the skills thot they have learnt in class. And also to kind of show the teacher ond the parent and the child
how to further enhance comprehension. You go from learning sentences to reaching a level where you have o proper conversation.

I think incentives in schools such as prizes, awards and competitions may motivate parents to take learning Arabic more seriously and solidify it in all schools in Dubai. back to work, it might be more motivating for me. Like my husband for instance, he took some classes in Arabic and you do come across Arab people and Arabic language. S

Perceived difficulty of the language: In my opinion, it is not a difficult language to learn. For instance my daughter learnt it and she is fairing well in it. I think the desire and interest in learning Arabic is my de Sal can understand why some would perceive it that way. Perceived Parents' Roles: I am learning Arabic with my daughters and I checked with the teacher regularly because I do not know if my daughters are doing it right? I have also considered hiring a tutor to improve my kids' learnin

I would definitely, sign up for a language course. Coming here I was puzzled of where to go and what to learn, there are different dialects. If there was a course offered to parents, that would be great.

Improvements and suggestions: I think there is a gap in communicating what our children are learning especially that parents need to know what words were covered and what they mean. Having the worksheets will help us help our kids in learning at home.

\section{Parent 3 Profile}

- American mother of one daughter

- First language is English

Indian Muslim heritage

Mother tongue is Hindi

onths paid by her

One daughter in Year 2

vears in school so far

She enjoys her Arabic lessons

She loves her teacher.

She is doing her Arabic homework and loves to do it

7 Parent is not aware of the framework for AAL

Parent's Attitudes towards learning languages in general: I love learning languages. Though I was brought up in the US. Actually, l learnt to learn Hindi and a bit of French. Thive Arabic sones and Is to them, I do not always understand everything but I think it is important for our children to learn languages for their social life and interactions. When I was in Japan, no one spoke English and I had to understand. S@ it's very important to grasp a little from the language

Attitudes towards Arabic culture: I love everything about Arabic culture. They are very nice. I have lots of Arab friends, Emirati too. And I enjoy the culture, very nice. That's why I'm here for the last twenty years now.

Attitudes towards Arabic speakers: Arab people are very helpful and kind-hearted. They try to correct vour Arabic words and even in everything, they try to help. One day I remember that I needed help with my car and Arab people stopped to help me. 


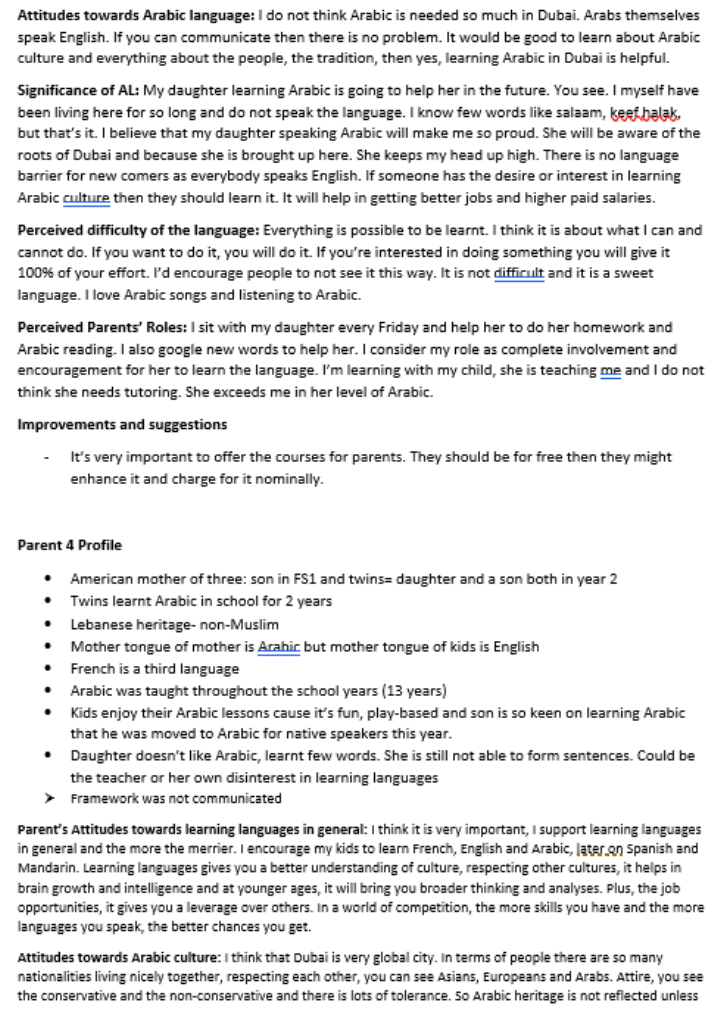

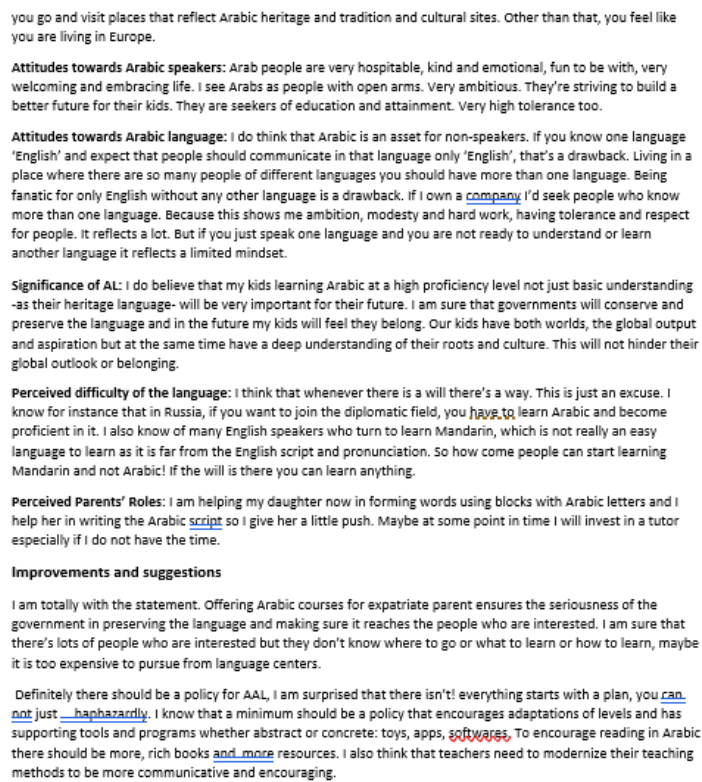

\section{REFERENCES}

[1] Ahmed, A. (2012, June 10). Children need better classes in Arabic. The National. Retrieved from https://www.thenational.ae/uae/education/children-need-better-classes-in-arabic-1.372961.

[2] Al-Alili, S. \& Hassan, W. (2017). Attitudes of Arabic and non-Arabic speaking parents toward the importance of learning Arabic in the United States. Journal of the National Council of Less Commonly Taught Languages, 21(unknown), 1-36. Retrieved from: http://www.ncolctl.org/files/Jncolctl-vol-21/Attitudes\%20of\%20Arabic-\%20and\%20NonArabic\%20Speaking\%20Parents\%20.pdf.

[3] Al-Hilali, Z. (2014). Towards enhancing the status quo of Arabic as a foreign language (AFL). Paper presented at The 5th Annual Gulf Comparative Education Society Symposium, The Gulf Comparative Education Society, Dubai, 86-94. Retrieved from https://www.researchgate.net/profile/Zeineb_AlHilali/publication/275462600_Towards_Enhancing_the_Status_Quo_of_Arabic _as_a_Foreign_Language_AFL_April_2014/links/553cdb1c0cf2c415bb0b8ce6/Towards-Enhancing-the-Status-Quo-of-Arabicas-a-Foreign-Language-AFL-April-2014.pdf (accessed 18/November/2019).

[4] Sambidge, A. (2012, April 23). UAE aims to be a global hub for Arabic language. Arabian Business. Retrieved from https://www.arabianbusiness.com/uae-aims-be-global-hub-for-arabic-language-455051.html.

[5] Baker, F \& Hourani, R. (2014). The nature of parental involvement in the city of Abu Dhabi in a context of change: Nurturing mutually responsive practice. Education, Business and Society: Contemporary Middle Eastern Issues, 7(4), 186-200. https://doi.org/10.1108/EBS-05-2014-0023.

[6] Bell, J. (2016, Sep 24). Children want to learn Arabic but classes are not up to speed: Parents. The National Newspaper. Retrieved from https://www.thenational.ae/uae/education/children-want-to-learn-arabic-but-classes-are-not-up-to-speedparents-1.189120.

[7] Bourdieu, P. (1991). Language and symbolic power. Cambridge: Polity Press.

[8] Calafato, R., \& Tang, F. (2019). The status of Arabic, superdiversity, and language learning motivation among non-Arab expats in the Gulf. Lingua, 219, 24-38. https://doi.org/10.1016/j.lingua.2018.11.003.

[9] Clarke, K. (2016, Dec 5). Arabic in UAE schools: the needs and the challenges. Khaleej Times. Retrieved from https://www.khaleejtimes.com/nation/education/should-arabicbecome-a-compulsory-language-in-uae-schools.

[10] Creswell, J.W. (2012). Educational research: planning, conducting and evaluating quantitative, and qualitative research (4 ${ }^{\text {th }}$ ed.). Boston: Pearson.

[11] Dornyei, Z. (2005). The psychology of the language learner: individual differences in second language acquisition. London: Lawrence Erlbaum Associates.

[12] Dubai Statistics Center. (2016). Retrieved from the Government of Dubai website. Retrieved from https://www.dsc.gov.ae/enus/Themes/Pages/Population-and-Vital-Statistics.aspx?Theme $=42$.

[13] Emirates 24/7. (2018, Dec 19) Sheikh Mohammed orders status report on Arabic language. Emirates 24/7 Newspaper. Retrieved from https://www.emirates247.com/news/government/sheikh-mohammed-orders-status-report-on-arabic-language2018-12-19-1.676808 
[14] Expat Echo Dubai. (na). Arabic in foreign private schools. Retrieved from http://www.expatechodubai.com/new-todubai/schools-new-to-dubai/arabic-in-foreign-private-schools/.

[15] Fan, X., \& Chen, M. (2001). Parental involvement and students' academic achievement: a meta-analysis. Educational Psychology Review, 13(1), 1-22. https://doi.org/10.1023/A:1009048817385.

[16] Fowler, F. C. (2013). Policy studies for educational leaders: An introduction. Boston, MA: Pearson Education.

[17] Gardner, R.C. (2010). Motivation and Second Language Acquisition: The Socio-Educational Model. New York: Peter Lang Publishing, Inc.

[18] Gardner, R. C., \& Lambert, W. E. (1972). Attitudes and motivation in second language learning. Rowley: MA Newbury House Publishers.

[19] Glesne, C. (2011). Becoming qualitative researchers: an introduction (4th ed.). Boston, MA: Pearson.

[20] Guba, E. \& Lincoln, Y. (1994). Competing paradigms in qualitative research. In Denzin, N. and Lincoln, Y. (Eds), Handbook of Qualitative Research. Thousand Oaks: Sage, 105-170.

[21] Habibis, D. (2013). Ethics and social research. In Walter, M ( $3^{\text {rd }}$ ed), Social research methods. South Melbourne: Oxford University Press, 72-98.

[22] Hamidaddin, H. A. (2008). Important factors to consider for bilingual education in the UAE (MA Thesis). American University of Sharjah. Retrieved from https://dspace.aus.edu:8443/xmlui/handle/11073/54 (accessed 19/December/2019).

[23] Heck, R. H. (2009). Studying educational and social policy: theoretical concepts and research methods. London: LEA Publishers.

[24] Husseinali, G. (2006). Who is studying Arabic and why? A survey of Arabic students' orientations at a major university. Foreign Language Annals, 39(3), 395-412. https://doi.org/10.1111/j.1944-9720.2006.tb02896.x.

[25] KHDA. (2019). Curriculum requirements for private schools in Dubai. Retrieved from https://www.khda.gov.ae/CMS/WebParts/TextEditor/Documents/Curriculum_Requirements_for_Private_Schools_in_Dubai_E ng.pdf (accessed 28/November/2019).

[26] KHDA. (2017). Executive council resolution no. 2 of 2017: regulating regulations private schools in the emirate of Dubai. Retrieved from https://www.khda.gov.ae/CMS/WebParts/TextEditor/Documents/ExecutiveCouncilResolutionNo.(2)of2017RegulatingPrivateS choolsIntheEmirateOfDubai.pdf (accessed 17/November/2019).

[27] KHDA. (2016). Educating hearts and minds: how to open a private school in Dubai. Retrieved from https://www.khda.gov.ae/CMS/WebParts/TextEditor/Documents/Educating_Heart_and_Minds.pdf (accessed 1/November/2019).

[28] Knowledge Group. (2016). Raising the quality of Arabic and Islamic education in UAE schools: a qualitative analysis of school inspection reports. [White Paper]. Retrieved from https://www.knowledgegroup.co/enus/ResearchInsights/Publication/WhitePapers/Documents/KG\%20Islamic\%20and\%20Arabic\%20White\%20Paper\%20SM.pdf (accessed 10/December/2019).

[29] Kohlbacher, F. (2006). The use of qualitative content analysis in case study research. Forum Qualitative Sozialforschung / Forum: Qualitative Social Research, 7(1). http://dx.doi.org/10.17169/fqs-7.1.75

[30] Kvale, S. (2007). Doing interviews. London: Sage.

[31] Lesnik, S., Brumen, M., \& Grmek, M. (2013). Attitudes of parents toward learning foreign languages- a slovene case study. New Educational Review, 34(4), 52-62. Retrieved from: https://tner.polsl.pl/dok/volumes/tner_4_2013.pdf\#page=52.

[32] Machi, L. \& McEvoy, B. (2012). The Literature Review: six Steps to Success. USA: Corwin.

[33] Martin, N. (2009). Arab American parents' attitudes toward their children's heritage language maintenance and language practices (MA Thesis). University of Carolina. Retrieved from https://search-proquestcom.dbgw.lis.curtin.edu.au/docview/304961324?accountid=10382 (accessed 22/November/2019).

[34] Mertens, D. (1998). Research methods in education and psychology. USA: Sage.

[35] Ministry of Education. (2017). Ministry of Education framework for learning Arabic as an additional language. Retrieved From https://www.moe.gov.ae/Ar/ImportantLinks/Assessment/Pages/Curriculum-Docs.aspx (accessed 15/November/2019).

[36] Naderifar, M., Goli, H., \& Ghaljaie, F. (2017). Snowball sampling: a purposeful method of sampling in qualitative research. SDME, 14(3), 1-6. DOI 10.5812/sdme.67670.

[37] Oskamp, S., \& Schultz, P. W. (2005). Attitudes and opinions. Mahwah, NJ: Lawrence Erlbaum Associates.

[38] Randall, M. \& Samimi, M. (2010). The status of English in Dubai. English Today, 26(1), 43-50. https://doi.org/10.1017/S0266078409990617.

[39] Sanders, M. G., \& Epstein, J. L. (2005). School-family-community partnerships and educational change: International perspectives. Extending Educational Change, 202-222. https://doi.org/10.1007/1-4020-4453-4_10.

[40] Sehlaoui, A., \& Mousa, R. (2016). Parents' perceptions of heritage languages in the mid-west: facing the challenge of losing one's native language in Kansas. The Advocate, 23(2), 33-55. https://doi.org/10.4148/2637-4552.1037.

[41] Silverman, D. (2013). Doing qualitative research. London: Sage.

[42] Smith, A.N. (1971). The importance of attitude in foreign language learning. Modern Language Journal, 55(2), 83-88. DOI: $10.2307 / 321854$.

[43] Souza, S. \& Del Olmo, F. (2019). A reflection on the concepts and the perceptions of language policy. Education and Linguistics Research, 5(1), 22-29. https://doi.org/10.1111/j.1464-410X.2009.08427.x.

[44] Taha-Thomure, H. (2008). The status of Arabic language teaching today. Education, Business and Society: Contemporary Middle Eastern Issues, 1(3), 186-192. https://doi.org/10.1108/17537980810909805.

[45] UAE Government. (2018). Curricula and Language of Instruction [online]. Retrieved from https://government.ae/en/information-and-services/education/school-education-k-12/joining-k-12-education/curricula-andlanguage-of-instruction- (accessed 22/December/2019).

[46] UAE Vision 2021. (2019). [Online]. Retrieved from https://www.vision2021.ae/docs/default-source/default-documentlibrary/uae_vision-arabic.pdf?sfvrsn=b09a06a6_6 (accessed 13/November/2019). 
[47] Walter, M. (2013). Social research methods ( $3^{\text {rd }}$ ed.). South Melbourne: Oxford University Press.

[48] Wilson, A. E. (2012). Interpreting differences in parental encouragement to learn the host language: California and Catalonia compared. Bellaterra Journal of Teaching \& Learning Language \& Literature, 5(3), 44-56. https://doi.org/10.5565/rev/jt13.469.

[49] Warner, R. \& Burton, G. (2017). A fertile oasis: the current state of education in the UAE. MBRSG. White Paper. Retrieved from: https://www.mbrsg.ae/getattachment/658fdafb-673d-4864-9ce1-881aaccd08e2/A-Fertile-OASIS-The-current-state-ofEducation-in.aspx (accessed 30/October/2019).

[50] Young, A. S. (1994). Motivational state and process within the socio-linguistic context (Unpublished PhD Thesis). Birmingham: Aston University.

[51] Zabarah, H. (2015). College-level Arabic heritage learners: do they belong in separate classrooms? Journal of National Council of Less Commonly Taught Languages, 18, 93-120. DOI 10.10119/issn.1930-9031.2016.03.08.

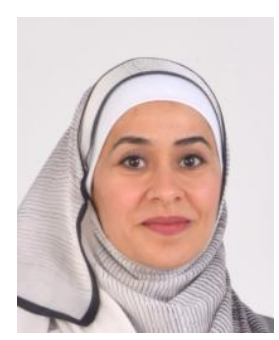

Reem J. Razem is a PhD in Education candidate at the British University in Dubai, specializing in second language acquisition and intercultural communicative competence (ICC). She obtained her Master's in education from Murdoch University, Dubai, UAE in 2018, her Teaching Arabic as a Foreign Language (TAFL) certificate from Georgetown University, USA in 2008, Cambridge CELTA qualification from Wollongong University in Dubai, in 2006, MA in American studies from the University of Jordan, Amman, Jordan in 2003, and her B.A. in political science from the University of Jordan, Amman, Jordan in 2001.

She currently holds the position of Lecturer in the School of Arts, Media and Mass Communication at Curtin University, Dubai, UAE. She also worked as a Lecturer at the University of Wollongong in Dubai, Middlesex University, the Canadian University of Dubai, and as a Research Coordinator at the Gulf Research Center in Dubai. Previous publications include: Co-authored a chapter on political developments in the UAE in 'The Year That Was: 2004' book (Dubai, UAE: Gulf Research Center, 2005), and published an article titled 'Arab Freedom Report Still in Chains' (Dubai, UAE: Gulf in the Media, Gulf Research Center, 2005). 